\title{
POTENCIAL DOS AQÜÍFEROS FRATURADOS DO ESTADO DE SÃO PAULO: CONDICIONANTES GEOLÓGICOS
}

\author{
PRODUCTION CAPACITY OF THE FRACTURED AQUIFERS OF THE STATE OF SÃO PAULO: \\ GEOLOGICAL CONTROLS
}

\author{
Amélia J. Fernandes ${ }^{1}$, Mônica M. Perrotta ${ }^{2}$, Elizete D. Salvador ${ }^{2}$, \\ Sérgio G. Azevedo ${ }^{3}$, Antonio Gimenez Filho ${ }^{3}$ e Nivaldo Paulon ${ }^{3}$
}

\begin{abstract}
RESUMO Existe grande dificuldade em prever o comportamento hidraúlico dos aquíferos fraturados devido à grande descontinuidade e heterogeneidade que caracteriza estes meios. Como consequiência, não existe método amplamente aceito para realizar o seu mapeamento, seja com relação às suas potencialidades como vulnerabilidades. Assim, para atender ao objetivo principal do Mapa de Águas Subterrâneas do Estado de São Paulo, que foi o de cartografar e representar áreas com potencialidades hidrogeológicas distintas dentro de cada aquífero estudado, foi necessário o desenvolvimento de um método que consistiu na avaliação da variação da capacidade específica de poços selecionados com relação aos seguintes fatores: conjuntos litológicos, espessura de manto inconsolidado, densidade e intersecção de lineamentos e blocos geológicos. Como resultado, foram individualizadas quatro classes de potencial hidrogeológico, sendo que três destas correspondem à subdivisão das rochas pré-cambrianas não carbonáticas, cujas medianas de capacidade específica são 0,04 $\mathrm{m}^{3} / \mathrm{h} / \mathrm{m}, 0,08 \mathrm{~m} 3 / \mathrm{h} / \mathrm{m}$ (os diabásios eocretáceos estão englobados nesta classe) e $0,18 \mathrm{~m}^{3} / \mathrm{h} / \mathrm{m}$. Na classe mais produtiva foram agrupadas rochas pré-cambrianas carbonáticas e basaltos eocretáceos, com medianas de 0,62 e $1,25 \mathrm{~m} / \mathrm{h} / \mathrm{m}$, respectivamente. Os limites entre as regiões de rochas pré-cambrianas que apresentam produção distinta correspondem principalmente a importantes zonas de cisalhamento, que delimitam em parte terrenos com evolução geológica distinta, e secundariamente a descontinuidades francamente rúpteis.
\end{abstract}

Palavras chave: aqüíferos fraturados, Estado de São Paulo, potencialidade de produção, rochas pré-cambrianas, basaltos eocretáceos

\begin{abstract}
As a consequence of the dificulty in predicting the hydraulic behaviour of the fractured aquifers, due to their descontinuity and heterogeneity, there is not, up to this moment, any generally accepted method to map this type of media, in terms of both potenciality and vulnerability. In this way, in order to meet the main goal of the Hydrogeological Map of the State of São Paulo, namely, delimitate areas with different goundwater production potentiality, it was necessary to develop a method which consisted on the evaluation of the specific capacity variation of selected wells with regard to: lithologic groups, thickness of the non-consolidated materials (regolith, soil and sediments), density and intersection of lineaments, and geological blocks. As a result, four classes of hydrogeological potential were characterized, three of them corresponding to the subdivision of the non-carbonatic Precambrian rocks, whose specific capacity medians are 0,04 $\mathrm{m}^{3} / \mathrm{h} / \mathrm{m}, 0,08 \mathrm{~m}^{3} / \mathrm{h} / \mathrm{m}$ (the Eocretaceous diabases are encompassed by this class) and $0,18 \mathrm{~m}^{3} / \mathrm{h} / \mathrm{m}$. The most productive class encompasses carbonatic Precambrian rocks and Eocretaceous basalts, with medians of 0,62 and 1,25 m/h/m, respectively. The boundaries between regions of pre-cambrian rocks with distinct production capacity correspond mainly to important shear zones, which partialy delimitate terrains with different geological evolutions, and secondarily to brittle discontinuities.
\end{abstract}

Keywords: fractured aquifers, State of São Paulo, production potentiality, Precambrian rocks, basalts

\section{INTRODUÇÃO}

O trabalho aqui apresentado resultou do projeto de elaboração do Mapa de Águas Subterrâneas do Estado de São Paulo na escala 1:1.000.000 (Governo do Estado de São Paulo 2005), elaborado em conjunto pelo Departamento de Águas e Energia Elétrica do Estado de São Paulo (DAEE), Instituto Geológico (IG-SMASP), Instituto de Pesquisas Tecnológicas do Estado de São Paulo (IPT), e Serviço Geológico do Brasil (CPRM). O projeto teve por objetivo realizar o zoneamento dos aqüíferos sedimentares e dos aquíferos fraturados do Estado de São Paulo, indicando vazões exploráveis, para os primeiros, e vazões prováveis, para os segundos.
A investigação de possíveis zoneamentos de potencial em aqüíferos fraturados constitui um grande desafio devido à descontinuidade de suas propriedades hidráulicas e à inexistência de método consagrado para tal. Desta forma, foi necessário desenvolver metodologia compatível com os dados e cartografias existentes, sendo que, neste trabalho, são detalhados os procedimentos de análise utilizados. A avaliação da potencialidade dos aqüíferos fraturados, que ocupam $37 \%$ do território do Estado, consistiu em verificar como a produtividade dos poços

\footnotetext{
${ }^{1} I G-$ Instituto Geológico

${ }^{2}$ CPRM - Serviço Geológico do Brasil

${ }^{3} \mathrm{IPT}$ - Instituto de Pesquisas Tecnológicas
} 
varia com relação a fatores considerados significativos, como conjuntos litológicos, estruturas rúpteis, espessura de material inconsolidado e blocos geológicos hidraulicamente homogêneos.

\section{OS AQÜÍFEROS FRATURADOS DO ESTADO DE SÃO PAULO}

No Estado de São Paulo ocorrem quatro tipos de aquíferos fraturados. O aquífero aflorante na porção leste do Estado de São Paulo, denominado de Pré-Cambriano (p€) (Figura 1), é constituído por rochas pré-cambrianas, com grau metamórfico variado, para e ortoderivadas, e rochas graníticas neoproterozóicas, maciças ou foliadas. Localmente ocorrem rochas intrusivas fanerozóicas englobadas neste conjunto por apresentarem comportamento hidráulico similar às rochas pré-cambrianas. $\mathrm{O}$ potencial de produção de águas subterrâneas do Aqüífero PréCambriano (p€) é, de um modo geral, mais baixo que o dos aquíferos granulares, no entanto, é de grande importância para o abastecimento local de, por exemplo, indústrias, propriedades rurais e condomínios. É importante lembrar que grandes centros urbanos, tais como a Grande São Paulo e as regiões metropolitanas de Campinas e Sorocaba, encontram-se atualmente em franca expansão sobre este aqüífero. $\mathrm{O}$ segundo tipo de aqüífero fraturado denominado Pré-Cambriano Carbonático $(p € c)$ consiste de mármores e metacalcários que afloram principalmente no sul do Estado (Figura 1).

O terceiro tipo de aqüífero fraturado, denominado Aquífero Serra Geral (Ksg), corresponde aos basaltos eocretácicos da Formação Serra Geral, que ocorrem em faixa irregular na porção central do Estado (Figura 1). Os basaltos apresentam espessuras que variam desde poucos metros até cerca de $300 \mathrm{~m}$ em sua área aflorante. Em subsuperfície chegam a alcançar espessuras superiores a $1500 \mathrm{~m} \mathrm{em}$ Presidente Epitácio (ALMEIDA, 1964) e atingem quase $2000 \mathrm{~m}$ na região do Pontal do Paranapanema (MILANI, 2004), ambas no oeste paulista. A profundidade do topo dos basaltos pode ser deduzida a partir das cotas de profundidade da base do Aqüífero Bauru (MANCUSO; CAMPOS, 2005).

Sobre os basaltos da Formação Serra Geral estão instalados importantes centros econômicos do interior do Estado, tais como Ribeirão Preto, Araraquara e São Carlos. O Aqǘf́fero Serra Geral sobrepõe-se ao Guarani e é recoberto pelo Bauru (Figura 1), apresentando potencial de produção muito maior que o do Aqüífero Pré-Cambriano (p€), como será apresentado adiante.

Finalmente, o quarto tipo de aqüífero, denominado Aquífero Diabásio (Ksgd), é constituído por corpos de diabásio, que ocorrem sob a forma de soleiras e diques, correlatos intrusivos aos basaltos da Formação Serra Geral. Apresentam ocorrência restrita, mas de grande importância local, e podem ser identificados como manchas em meio aos aqüíferos Tubarão e Guarani e Aqüiclude Passa Dois. Diques intrusivos em rochas pré-cambrianas ocorrem em grande quantidade no extremo sul do Estado, onde apresentam direção preferencial N40-50W (Almeida 1964). Seu comportamento hidráulico ainda não é bem conhecido, no entanto, sabe-se que podem atuar como barreira ou como condutos de circulação mais rápida de água subterrânea.

Neste trabalho foi utilizado como base o Mapa Geológico do Estado de São Paulo, na escala 1:750.000 da CPRM (PERROTTA et al. 2005), onde são encontradas descrições mais detalhadas das rochas que compõem os aqüíferos. 


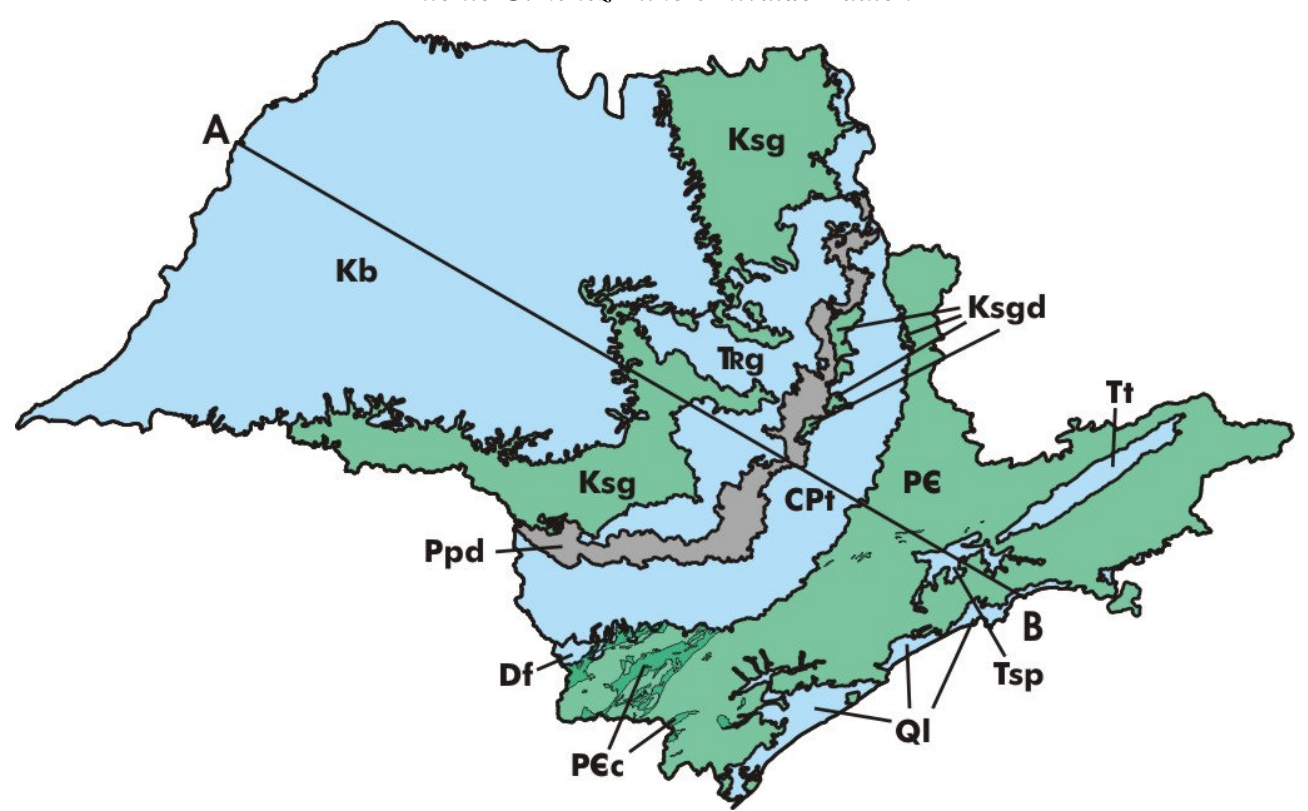

A

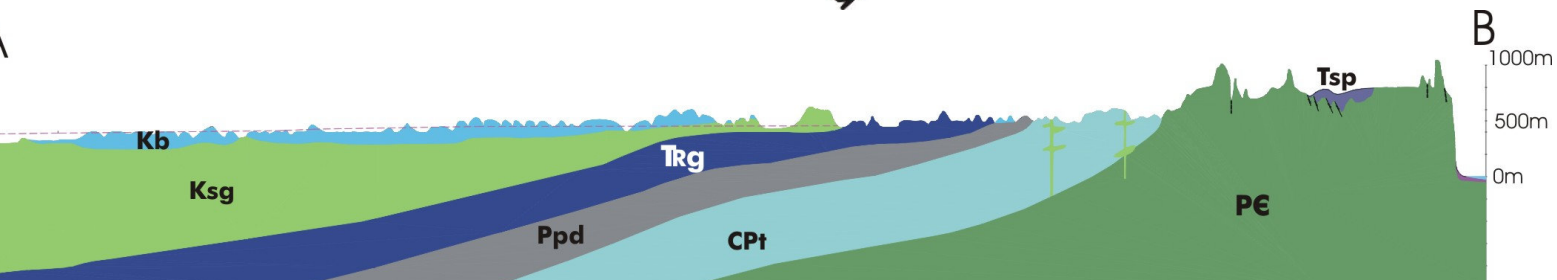

Figura 1. Mapa e seção hidrogeológica esquemáticos dos aqüíferos paulistas. Do mais antigo para o mais jovem: préCambriano (P€), pré-Cambriano cárstico (P€c), Furnas (Df), Tubarão (CPt), Aqüiclude Passa Dois (Ppd), Guarani (TRg), Serra Geral (Ksg), Serra Geral Diabásio (Ksgd), Bauru (Kb), São Paulo (Tsp), Taubaté (Tt), Litorâneo (Ql).

Figure 1. Schematic map and hydrogeological section of the aquifers of the State of São Paulo. From de oldest to newest: Precambrian (P€), Precambrian carstic (P€c), Furnas (Df), Tubarão (CPt), Aquiclude Passa Dois (Ppd), Guarani (TRg), Serra Geral (Ksg), Serra Geral Diabase (Ksgd), Bauru (Kb), São Paulo (Tsp), Taubaté (Tt), Litorâneo (Ql).

\section{MÉTODOS}

A avaliação da potencialidade dos aqüíferos fraturados consistiu em verificar como a produtividade de poços selecionados varia com relação a fatores considerados significativos, enumerados na tabela 1 e discutidos mais adiante. $\mathrm{O}$ parâmetro de produção de poços utilizado na análise foi a capacidade específica $\left(\mathrm{em} \mathrm{m}^{3} / \mathrm{h} / \mathrm{m}\right)$, por se considerar que esta, apesar de ser influenciável por aspectos construtivos dos poços, indica mais diretamente o potencial do aquífero, quando comparada à vazão. Nos estudos do DAEE $(1981,1982)$ foi verificada boa correlação entre capacidade específica e transmissividade do aqüífero fraturado local.

O banco de dados de poços utilizado resultou da organização de informações provenientes do DAEE e, subordinadamente, do IG-SMASP. Da totalidade dos poços cadastrados no banco foram utilizados apenas aqueles que apresentassem o valor da capacidade específica, gerando três bases de dados: a dos aqüíferos pré-cambrianos (p€ e p€c), com 1202 poços; a do Aqüífero Serra Geral (Ksg), com 285 poços, para a área aflorante da formação homônima; e a do Aqüífero Diabásio (Ksgd), com 49 poços. Na Figura 2 observa-se que existe uma grande quantidade de poços situados fora da área de afloramento da Formação Serra Geral, a maioria deles em área de ocorrência do Grupo Bauru, mas que explorariam o Aqüífero Serra Geral. Por existir a possibilidade de parte destes poços estarem sob influência ou explorarem o Aqüífero Bauru, estes dados não foram utilizados na análise aqui desenvolvida, no entanto, podem ser consultados tanto na base de dados do DAEE como na da CPRM. 
Tabela 1. Materiais e dados utilizados para a avaliação da potencialidade dos aqüíferos fraturados do Estado de São Paulo, com a citação da respectiva fonte e fator de análise extraído de cada material consultado.

\begin{tabular}{|l|l|l|}
\hline \multicolumn{1}{|c|}{$\begin{array}{l}\text { Materiais ou } \\
\text { dados }\end{array}$} & \multicolumn{1}{|c|}{ Fonte } & \multicolumn{1}{c|}{ Fator analisado } \\
\hline $\begin{array}{l}\text { Base de dados } \\
\text { de poços }\end{array}$ & $\begin{array}{l}\text { DAEE e } \\
\text { subordinadamente } \\
\text { IG - SMA }\end{array}$ & Capacidade específica $(\mathrm{m} / \mathrm{h} / \mathrm{m})$ \\
\hline $\begin{array}{l}\text { Mapa } \\
\text { Geológico do } \\
\text { Estado na } \\
\text { escala } \\
1: 750.000\end{array}$ & $\begin{array}{l}\text { PERROTTA } \text { et al. } \\
(2005)\end{array}$ & Conjuntos litológicos e blocos geológicos \\
\hline $\begin{array}{l}\text { Carta } \\
\text { geotécnica do } \\
\text { Estado na } \\
\text { escala } \\
1: 500.000\end{array}$ & $\begin{array}{l}\text { Instituto de } \\
\text { Pesquisas } \\
\text { Tecnológicas do } \\
\text { Estado - IPT }(1994)\end{array}$ & Espessura de manto inconsolidado \\
\hline $\begin{array}{l}\text { Mapa de } \\
\text { lineamentos }\end{array}$ & $\begin{array}{l}\text { Fernandes et al. } \\
(2005)\end{array}$ & $\begin{array}{l}\text { Densidade de lineamentos e densidade de intersecção de } \\
\text { lineamentos que, em geral, tem relação direta com a densidade } \\
\text { e intersecção de fraturas que ocorrem junto à superfície do } \\
\text { terreno }\end{array}$ \\
\hline
\end{tabular}

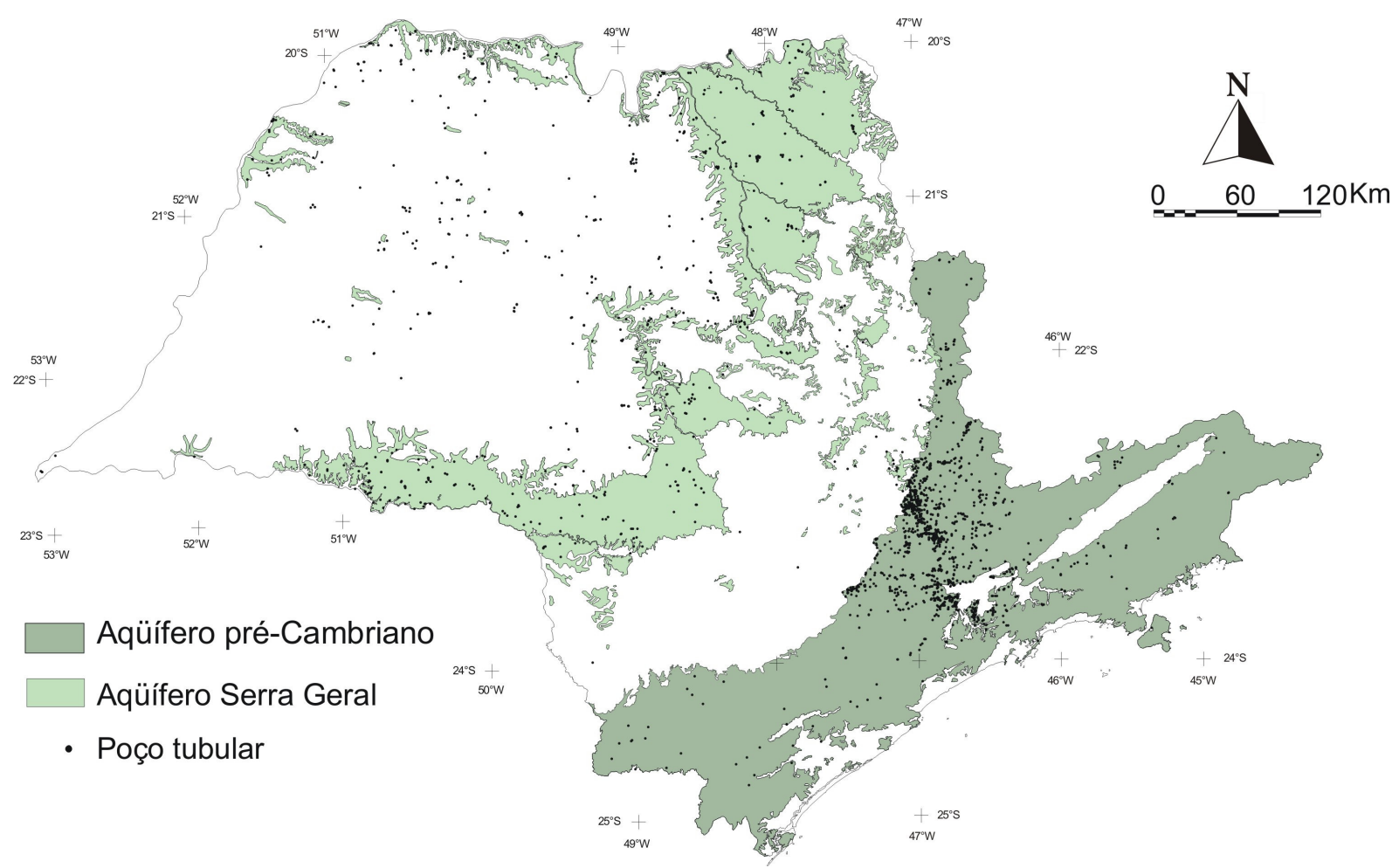

Figura 2. Localização das áreas de afloramento dos aqüíferos fraturados no Estado de São Paulo e distribuição dos poços que exploram os aquíferos p€, p€c e Ksg.

Figure 2. Location of the outcroping areas of the fractured aquifers of the State of São Paulo and the distribution of the wells that tap the aquifers $p €, p € c$ e Ksg.

Diversos são os fatores que exercem influência sobre a circulação e o armazenamento de água subterrânea em aquíferos fraturados (FERNANDES, 2006), no entanto, devido à escala de trabalho e aos dados disponíveis, optouse pela análise da variação da capacidade específica dos poços com relação aos seguintes fatores: conjuntos litológicos, blocos geológicos (ver Tabela 2 para definição), espessura de manto inconsolidado e densidade de lineamentos e densidade de intersecção de lineamentos. Para tal utilizou-se o seguinte procedimento: 
-Divisão da área dos aquíferos fraturados em classes segundo as subdivisões de cada fator considerado (Tabela 2);

-Agrupamento dos poços conforme as classes mencionadas;

-Avaliação do comportamento da produtividade de cada conjunto de poços através do cálculo da mediana (valor central) da capacidade específica e da construção de curvas de distribuição acumulada das capacidades específicas;

-Comparação das curvas de distribuição acumulada para verificar a existência de diferenças significativas entre as classes.

Tabela 2. Fatores considerados na avaliação da variação da produção dos poços e subdivisão destes fatores em classes.

\begin{tabular}{|c|c|}
\hline Fator considerado & Classes \\
\hline $\begin{array}{l}\text { Conjuntos } \\
\text { litológicos }\end{array}$ & $\begin{array}{l}\text { - Granitos neoproterozóicos } \\
\text { - Rochas metamórficas de médio a alto grau } \\
\text { - Rochas metamórficas de baixo a médio grau } \\
\text { - Rochas carbonáticas (calcário, mármore, marga) } \\
\text { - Basalto } \\
\text { - Diabásio }\end{array}$ \\
\hline $\begin{array}{l}\text { Espessura de } \\
\text { material } \\
\text { inconsolidado }\end{array}$ & $\begin{array}{l}\text { - Espesso }(>30 \mathrm{~m}) \\
\text { - De espessura intermediária }(\text { entre } 5 \text { e } 30 \mathrm{~m}) \\
\text { - Pouco espesso ou ausente }(<5 \mathrm{~m})\end{array}$ \\
\hline $\begin{array}{l}\text { Lineamentos } \\
\text { (fraturas) }\end{array}$ & $\begin{array}{l}\text { Densidade de lineamentos por direção (em metros) por células quadradas de } 5 \mathrm{~km} \text { de } \\
\text { lado: } \\
\text { - < } 4000 \\
\text { - entre } 4000 \text { e } 8000 \\
\text { - entre } 8000 \text { e } 12000 \\
\text { - entre } 12000 \text { e } 16000 \\
\text { - > } 16000 \\
\text { Densidade de intersecção de lineamentos (combinações possíveis entre as diversas } \\
\text { direções) em número de intersecções por km²: } \\
\text { - < } 0,05 \\
\text { - entre } 0,05 \text { e } 0,1 \\
\text { - entre } 0,1 \text { e } 0,15 \\
\text { - entre } 0,15 \text { e } 0,25 \\
\text { - > } 0,25\end{array}$ \\
\hline Blocos geológicos & $\begin{array}{l}\text { Blocos definidos pelo agrupamento ou subdivisão dos terrenos geológicos presentes no } \\
\text { Mapa Geológico do Estado de São Paulo. Os blocos são delimitados por zonas de } \\
\text { cisalhamento dúctil-rúpteis ou por lineamentos, que devem corresponder a estruturas } \\
\text { rúpteis de dimensões regionais. }\end{array}$ \\
\hline
\end{tabular}

A avaliação do fator "conjunto litológico" teve como base o Mapa Geológico do Estado de São Paulo, na escala 1:750.000 da CPRM (Perrotta et al. 2005), reclassificado em ambiente SIG (Sistema de Informações Geográficas) para as classes definidas na Tabela 2. Compreendem a classe de rochas metamórficas de médio a alto grau os Complexos Amparo, Serra Negra, Santa Catarina, Rio Capivari, Atuba, São Gonçalo do Sapucaí, Apiaí-Mirim, Varginha-Guaxupé, Costeiro, Paraíba do Sul e parte do Embu, o Grupo Andrelândia, o Ortognaisse Serra Negra, a Suíte Serra de São Gonçalo e o Batólito Paranaguá. A classe de rochas metamórficas de baixo a médio grau abrange as formações Piririca, Córrego dos Marques, Betari, Serra da Boa Vista, Abapã, Iporanga e parte da FurnasLageado e Água Clara, os grupos Votuverava, Serra do Itaberaba, São Roque e parte do
Itaiacoca, o Complexo Turvo-Cajati e parte da Unidade Serra das Andorinhas.

As classes de espessura do manto inconsolidado foram obtidas a partir da Carta Geotécnica do Estado de São Paulo na escala 1:500.000 (IPT 1994). Esta classificação foi realizada apenas para a área aflorante de rochas pré-cambrianas.

A avaliação do papel dos fatores "lineamentos" e "blocos geológicos" merecem uma descrição mais detalhada, como as que vêm a seguir.

\section{Fator "Lineamentos"}

A análise do fator lineamentos é uma forma indireta de avaliar a influência de fraturas, com relação a aspectos tais como densidade, conectividade e trends estruturais, na produção de poços em aqǘf́reros fraturados. Existem, no 
Estado de São Paulo, exemplos anteriores deste tipo de avaliação, tais como o de Fernandes (1997), Fernandes; Rudolph (2001), Perrotta; Salvador (2002, 2006), Takahashi et al. (2003) e Madrucci (2004). Vários outros trabalhos investigaram a influência das estruturas tectônicas e/ou lineamentos sobre a produção de poços (e.g. DAEE 1979, 1981, 1982, BERTACHINI 1987, MENEGASSE 1991) ou ainda sobre a delimitação de áreas de proteção de poços e fontes (IG 1997, Iritani et al. 1998, IG 2000) e elaboração de mapas de vulnerabilidade (IG 2002, FERNANDES 2003).

Neste trabalho foram gerados dois mapas de lineamentos: um da área de afloramento das rochas pré-cambrianas e outro da área de afloramento da Formação Serra Geral (Figuras 3 e 4). A extração de lineamentos compreendeu os seguintes procedimentos:

-Traçado de lineamento a partir de imagens LANDSAT TM-5 (cenas 219-76, 219-77, 218-76, 219-75 e 220-77), realizado manualmente sobre impressões em papel na escala 1:500.000, na composição das bandas 345, para a área aflorante dos aquíferos précambrianos (p€ e p€c). O traçado em imagens não foi realizado na área aflorante da Formação Serra Geral e dos diabásios, já que a suavidade do relevo não propicia, de um modo geral, sombreamento adequado e os limites entre propriedades rurais obscurecem feições que seriam visíveis. A interpretação foi feita em separado para quatro intervalos de direções (em torno de NE, NW, NS e EW), utilizando overlays distintos, de modo que o traçado de um intervalo não obscurecesse o dos demais. Os mapas resultantes foram digitalizados e vetorizados, com eliminação de traços duplicados provenientes ou das áreas de superposição entre as imagens ou dos diferentes overlays.

-Traçado de lineamentos sobre imagens de relevo sombreado geradas a partir do modelo digital de terreno (MDT) produzido na Missão Topográfica por Radar Interferométrico (Shuttle Radar Topographic Mission SRTM), nas áreas aflorantes dos aquíferos Serra Geral e Pré-Cambriano. Quatro imagens foram produzidas com fonte de iluminação artificial segundo azimutes $0^{\circ}, 45^{\circ}, 90^{\circ}$ e $315^{\circ}$, todas com elevação de $35^{\circ}$. Para extração digital dos lineamentos foi utilizado o programa ArcGIS ${ }^{\circledR}$ com escala fixa de exibição em 1:300.000, o que corresponde à visualização integral de uma folha 1:50.000 na tela. Na área dos aqüíferos pré-cambrianos os lineamentos interpretados foram integrados àqueles extraídos das imagens LANDSAT.

No Mapa de Águas Subterrâneas (Governo do Estado de São Paulo 2005) estão representados alguns dos lineamentos mais extensos e de maior expressão.

Nas rosáceas (Figuras 3 e 4), construídas através de rotina elaborada para o MAPINFO ${ }^{\circledR}$ (IG 2004), são verificados 5 trends principais de lineamentos com pequenas diferenças entre basaltos e rochas pré-cambrianas (Tabela 3). Para estas últimas, cada uma das direções é ilustrada individualmente, devido à alta densidade de traços obtida.

Foram elaborados mapas de densidade de lineamentos para cada um dos cinco intervalos de direções identificados, discriminados na Tabela 3, e mapas de densidade de intersecções, considerando todas as possíveis combinações de cruzamentos entre os trends preferenciais de lineamentos. Considera-se que, de um modo geral, estes parâmetros são diretamente proporcionais à densidade e conectividade de fraturas, respectivamente.

Os mapas de densidade de lineamentos foram construídos em ambiente SIG, através de método descrito abaixo, aplicado para cada um dos cinco intervalos de direção analisados, bem como para o conjunto de lineamentos traçados :

a) Segmentação da área analisada em células quadradas de $5 \mathrm{~km}$ de lado e contagem do comprimento acumulado de lineamentos por célula, através de rotina para MAPINFO ${ }^{\circledR}$ (IG 2004);

b) Transformação do arquivo de células (polígonos) em arquivo de pontos (centróides das células) preservando-se os atributos de comprimento acumulado para cada direção e total de lineamentos;

c) Produção dos mapas de densidade de lineamentos através de interpolação do arquivo de pontos no módulo Spatial Analyst do ArcGIS@, pelo método spline com os seguintes parâmetros: valor de Z comprimento acumulado de lineamentos para cada direção analisada, tipo - tension, peso $1, \mathrm{n}^{\mathrm{o}}$ de pontos -8 , tamanho da célula -500 $\mathrm{m}$. Como resultado são produzidos mapas em formato matricial (raster).

d) Reclassificação dos mapas de densidade em 5 classes (expostas na Tabela 2), segundo 
valores normalizados para todos os mapas, conforme quebras naturais mais comuns.

Os mapas de densidade de intersecções, entre pares de direções de lineamentos, conforme os intervalos de direções expostos na tabela 3 , foram construídos conforme o método descrito abaixo:

a) Produção dos mapas de pontos de intersecção entre pares de direções de lineamentos através de identificação automática dos pontos de intersecção em ambiente SIG. b) Produção do mapa de densidade de intersecções através da rotina density do módulo Spatial Analyst do ArcGIS@, sobre os arquivos de pontos gerados, segundo os seguintes parâmetros: campo da população nenhum, tipo de densidade - kernel, raio de busca -10000 , unidade de área $-\mathrm{km}^{2}$, célula de saída - 1000.

c) Reclassificação dos mapas de densidade produzidos segundo os intervalos de densidade expostos na Tabela 2, normalizados para todos os mapas, conforme quebras naturais mais comuns.
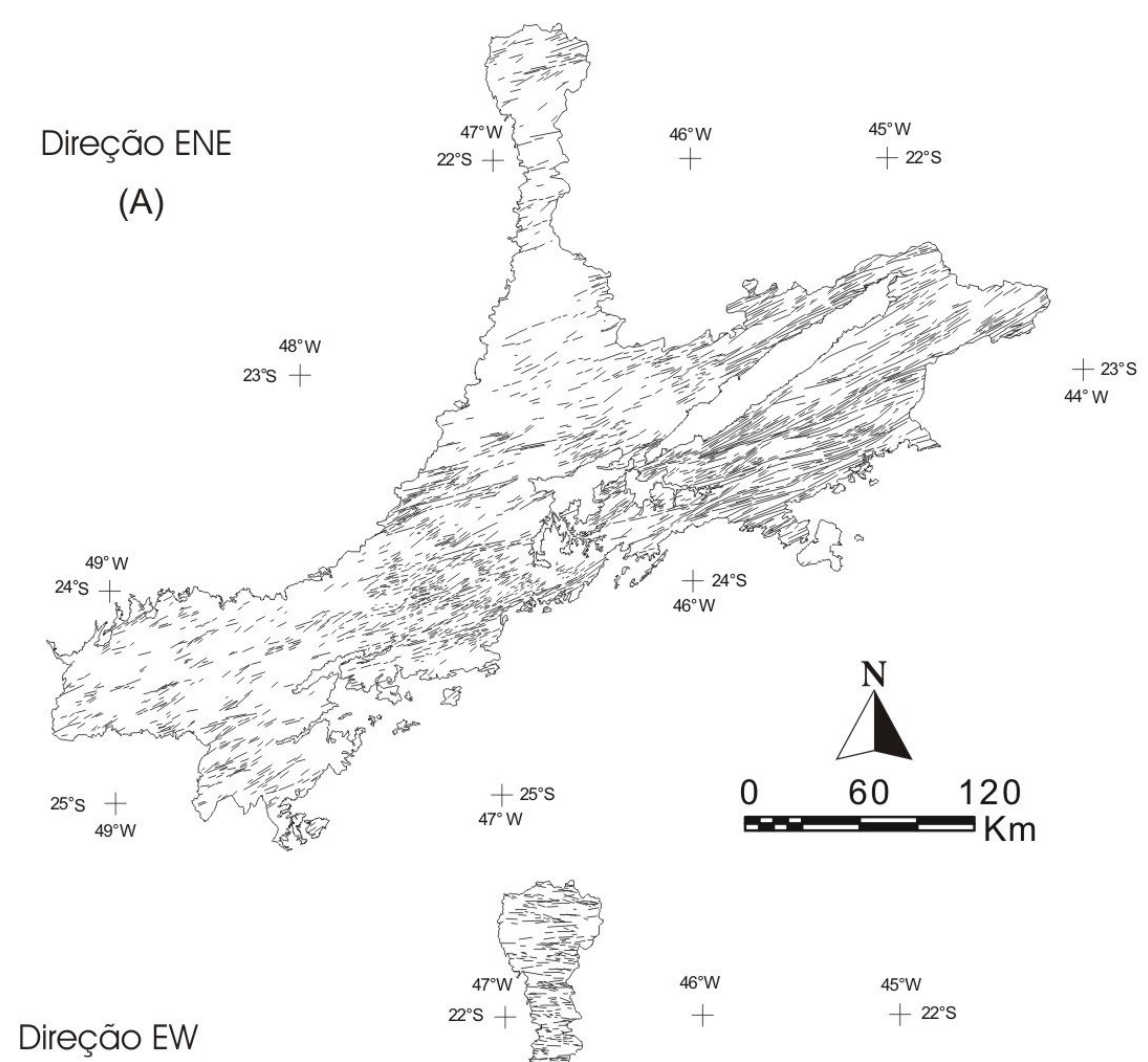

(B)

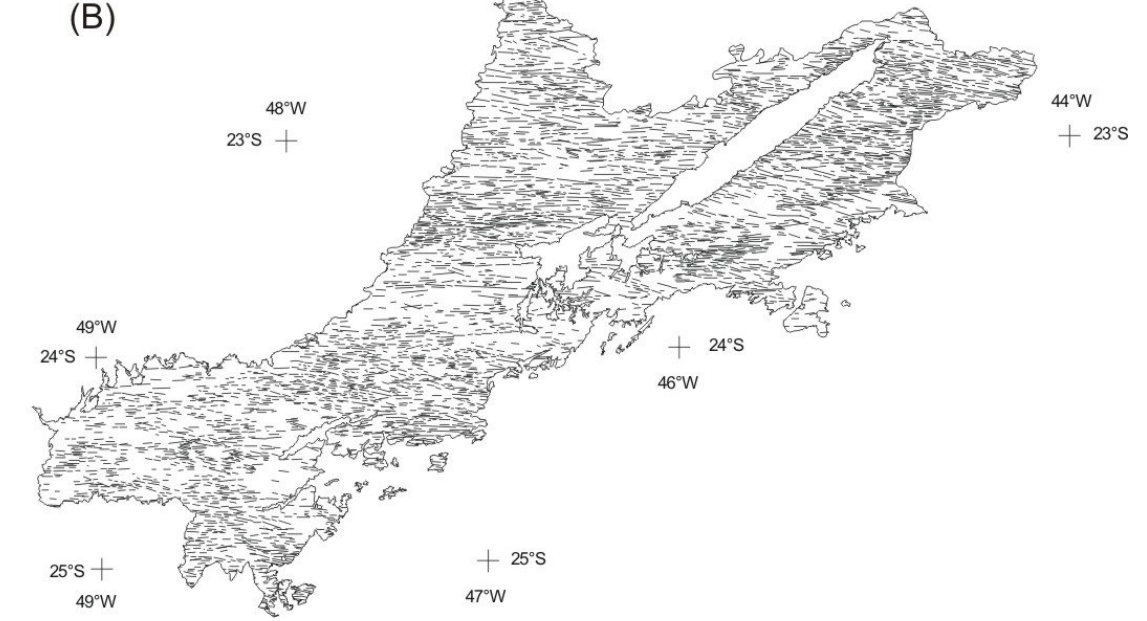

Figura 3. (A) a (E) Mapa de lineamentos das rochas pré-cambrianas do Estado e (F) rosácea de todos os lineamentos (por comprimento acumulado).

Figure 3. (A) to (E) Lineament maps of the Precambrian rocks of the State and $(F)$ total rose diagram of the lineaments (cumulative length) 




Figura 3. (A) a (E) Mapa de lineamentos das rochas pré-cambrianas do Estado e (F) rosácea de todos os lineamentos (por comprimento acumulado). (Continuação)

Figure 3. (A) to $(E)$ Lineament maps of the Precambrian rocks of the State and $(F)$ total rose diagram of the lineaments (cumulative length.) (Continuation) 

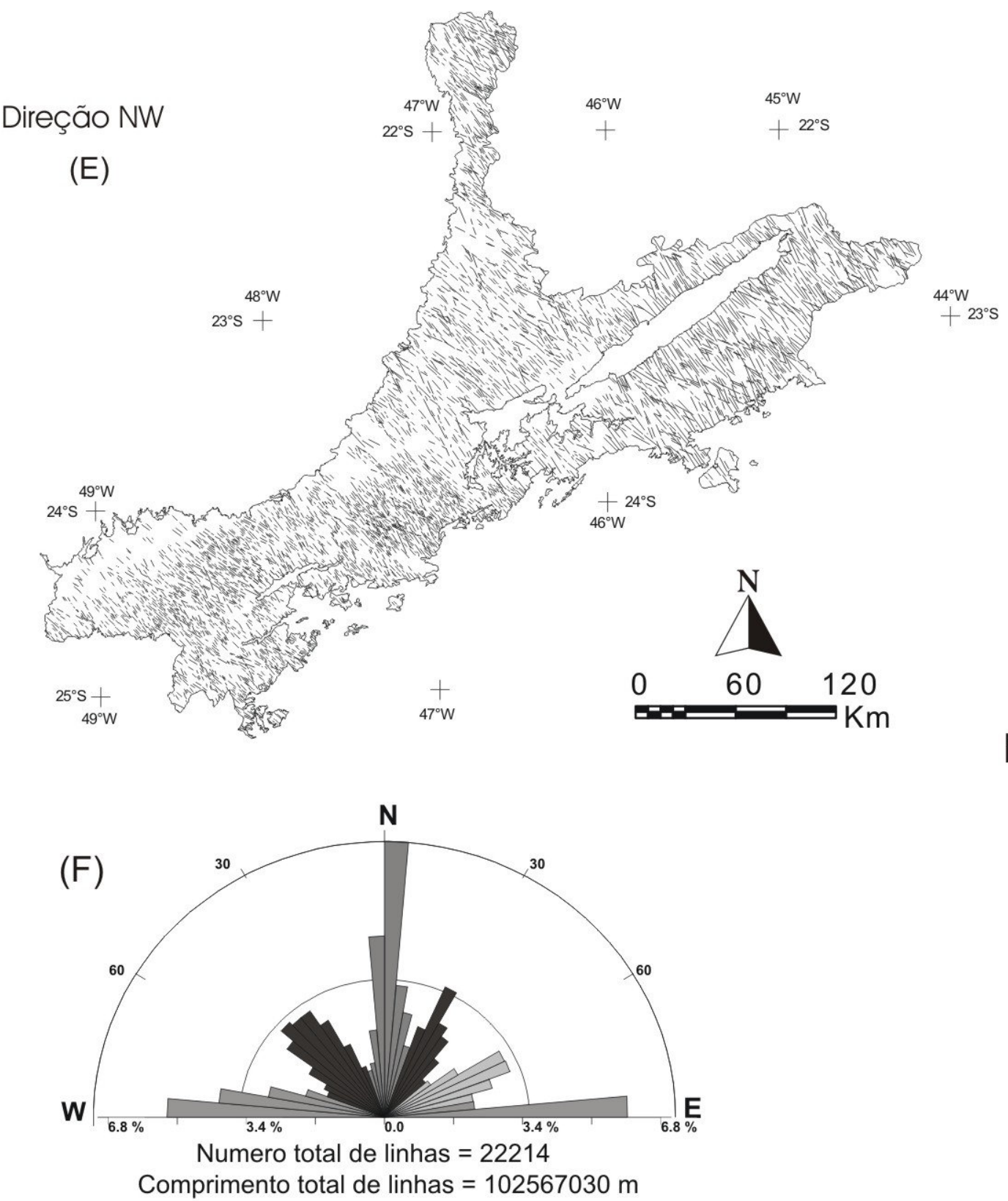

Figura 3. (A) a (E) Mapa de lineamentos das rochas pré-cambrianas do Estado e (F) rosácea de todos os lineamentos (por comprimento acumulado). (Continuação)

Figure 3. (A) to (E) Lineament maps of the Precambrian rocks of the State and $(F)$ total rose diagram of the lineaments (cumulative length.) (Continuation)

Tabela 3. Direções preferenciais de lineamentos em basaltos e rochas pré-cambrianas.

\begin{tabular}{|l|l|l|l|l|l|}
\hline \multicolumn{1}{|c|}{ Grupos de Rochas } & \multicolumn{5}{|c|}{ Intervalos de direções preferenciais em ordem decrescente de importância } \\
\hline Basaltos & N10W-N5E & N85E-N85W & N40-60W & N55-65E & N35-40E \\
\hline Rochas pré-cambrianas & N5W-N10E & N85E-N75W & N30-65W & N60-75E & N25-35E \\
\hline
\end{tabular}



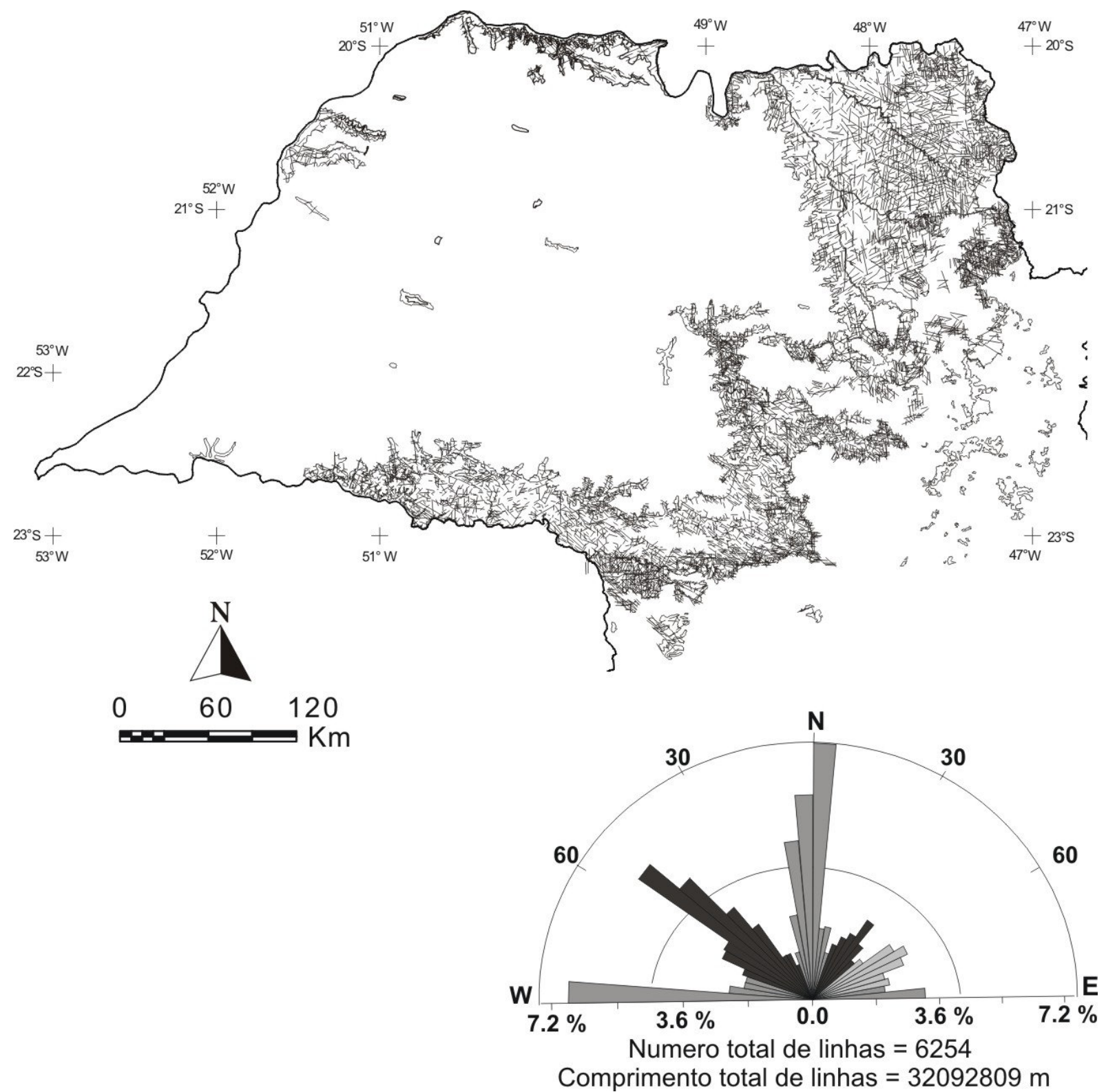

Figura 4. Mapa de lineamentos da área aflorante dos basaltos do Estado e rosácea de todos os lineamentos (comprimento acumulado).

Figure 3. (A) to (E) Lineament map of the basalt outcroping area of the State and $(F)$ total rose diagram of the lineaments (cumulative length.)

\section{Fator "Blocos geológicos"}

Procedeu-se à avaliação deste fator após ter sido notada variação significativa da produção de poços para a região de Campinas quando foram comparadas as distribuições acumuladas das capacidades específicas de poços situados a noroeste e a sudeste do limite do Terreno Socorro-Guaxupé com o Terreno Andrelândia, utilizando os dados de poços de IG (2002). Com base nesta observação, e utilizando os dados do cadastro presente em (Governo do Estado de São Paulo 2005), a produção de poços situados em terrenos geológicos pré-cambrianos distintos, definidos em Perrotta et al. (2005), foi sistematicamente avaliada para a porção central do Estado de São Paulo (aproximadamente eixo Campinas - São Paulo), região com maior densidade de dados de poços, e posteriormente estendida para as outras regiões dos aqüíferos pré-cambrianos, onde os dados são mais esparsamente distribuídos. A avaliação baseou-se na comparação das distribuições acumuladas das capacidades específicas de poços para os terrenos pré-cambrianos e para subdivisões destes, muitas vezes correspondentes aos corpos graníticos. Desta forma foram definidos blocos geológicos cujos limites podem ser de 3 tipos: (1) zonas de cisalhamento que delimitam terrenos geológicos; (2) lineamentos expressivos, discordantes das estruturas dúcteis pré-cambrianas, tratando-se 
portanto de prováveis estruturas rúpteis; e (3) contatos geológicos que são subparalelos aos limites dos terrenos, mas encontram-se deslocados com relação a estes. Como exemplo destes tipos de limites podem ser citados: zonas de cisalhamento que limitam o Terreno Embu na porção sudeste do Estado (tipo 1); lineamentos de direção NS, que passam por Itatiba e Campo Limpo Paulista (a norte da ZC Jundiuvira) (tipo 2); contato noroeste da bacia de Taubaté com as rochas pré-cambrianas (tipo 2). Também foram identificados outros limites que não coincidem nem com as zonas de cisalhamento dúctil-rúpteis nem com lineamentos importantes; estes limites apresentam principalmente a direção NW e secundariamente WNW e NS, passando por São Lourenço da Serra e próximo a São Bernardo do Campo (entre as ZCs Cubatão e Caucaia), próximo a Ibiúna (entre as ZCs Caucaia e Taxaquara), por Caieiras (entre ZCs Taxaquara e Jundiuvira) e próximo a Itupeva (a norte da ZC Jundiuvira). Após a análise descrita alguns blocos foram agrupados em função da similaridade das produções dos poços neles inseridos.

\section{RESULTADOS}

Neste item são apresentados os resultados obtidos a partir da análise da variação da capacidade específica dos poços com relação aos fatores conjunto litológico, espessura de manto inconsolidado, lineamentos e blocos geológicos, anteriormente discutidos e apresentados na Tabela 2.

Com relação ao fator conjunto litológico, as curvas de distribuição acumulada de capacidade específica dos diabásios, gnaisses (denominação simplificada para as rochas metamórficas de médio e alto grau) e rochas metamórficas de baixo grau (Figura 5) apresentam a mesma mediana (em torno de $0,09 \mathrm{~m}^{3} / \mathrm{h} / \mathrm{m}$ ) e curvas bastante próximas para os valores acima da mediana; os diabásios e as rochas metamórficas mostram-se menos produtivos que os gnaisses para os valores abaixo da mediana. Em termos práticos, no entanto, as distribuições destes três tipos litológicos indicam comportamento hidráulico semelhante. Os granitos apresentam produção menor, como evidenciado pela sua curva (Figura 5) e mediana de $0,06 \mathrm{~m}^{3} / \mathrm{h} / \mathrm{m}$, quando comparados aos gnaisses com mediana de $0,09 \mathrm{~m} / \mathrm{h} / \mathrm{m}$, no entanto, diferenças de produção ficam melhor caracterizadas com relação aos blocos geológicos, como será descrito adiante. Apesar da pequena quantidade de dados disponíveis para as rochas carbonáticas, estas, aparentemente, apresentam potencial semelhante ao dos basaltos, e bastante superior aos demais tipos de rocha. O potencial mais elevado é explicado por cavidades de dissolução nas rochas carbonáticas, como já amplamente conhecido, e por fraturas subhorizontais e mais transmissivas nos basaltos, aumentando a condutividade hidráulica e a capacidade de armazenamento de água destas rochas.

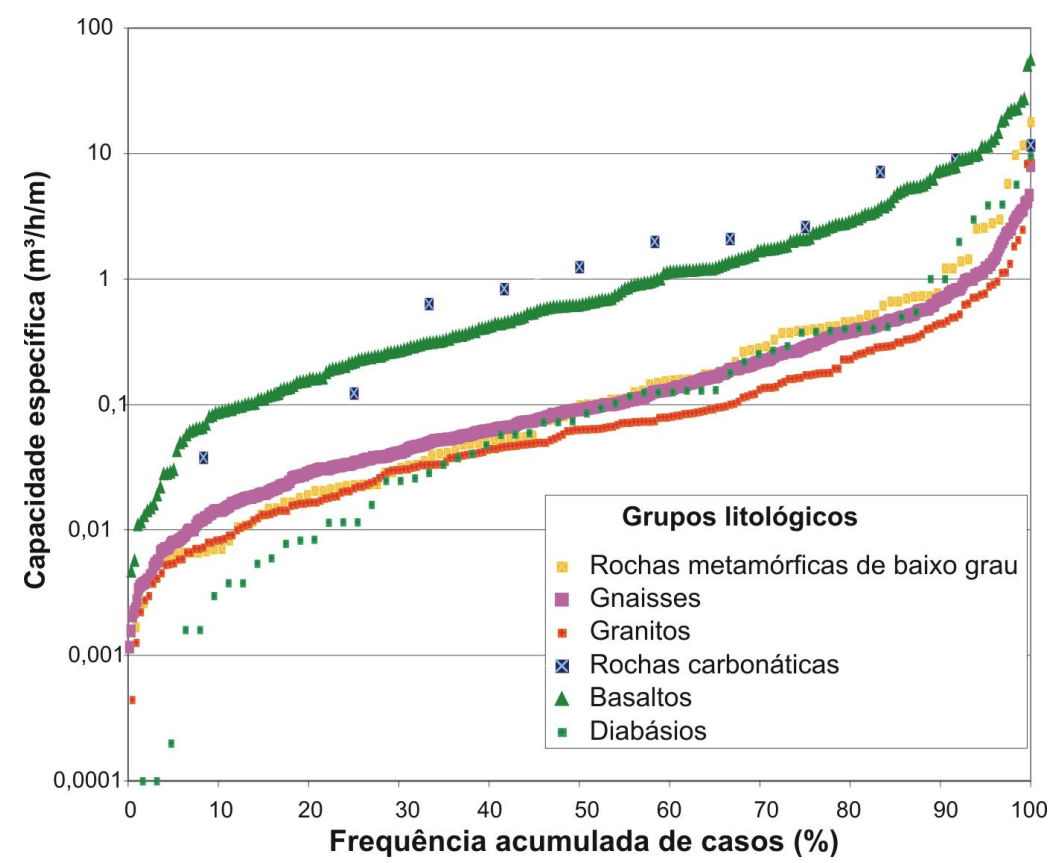

Figura 5. Curvas de distribuição acumulada obtidas para as várias classes de conjuntos litológicos que constituem os aquíferos fraturados do Estado de São Paulo.

Figure 5. Cumulative distributions obtained for the various lithologic sets that constitute the fractured aquifers of the State of São Paulo. 
A espessura de manto inconsolidado foi avaliada somente para as rochas pré-cambrianas do Estado e, nesta escala de análise, as curvas de distribuição acumulada de capacidade específica (Figura 6) mostram que o fator não exerce influência sobre a variação da produção de poços. Nota-se que as curvas dos poços localizados em áreas de classe manto espesso e dos poços na classe manto de espessura intermediária praticamente se sobrepõem. Com relação à classe manto pouco espesso ou ausente, os resultados não são conclusivos devido à pequena quantidade de poços localizados nestas áreas.

No que diz respeito à análise de lineamentos, correlações positivas com a capacidade específica de poços foram obtidas apenas nas áreas de alta densidade de lineamentos de direção EW e em áreas com alta densidade de intersecções entre as direções EW e NS (Figura 7). Este resultado é conclusivo apenas para a região localizada entre São Paulo e Campinas, onde existe uma maior densidade de poços. Para as demais áreas o resultado é apenas sugestivo devido à esparsa distribuição de poços..
A relação existente entre produção de poços e densidades de lineamentos e de intersecções de lineamentos também foi analisada para a área de ocorrência de basaltos, não tendo sido verificada qualquer correlação entre estes fatores. Tal fato deve-se, provavelmente, à maior condutividade hidráulica de fraturas horizontais e contatos entre derrames (como descrito em SINELLI, 1971; FARJALAT, 1974 apud REBOUÇAS, 1978; QUADROS et al,. 1991; TRESSOLDI, 1991) que, no entanto, não são identificáveis em imagens de sensores remotos, por não terem expressão na superfície do terreno sob a forma de lineamentos. A maior permeabilidade das estruturas horizontais mascararia, na escala de trabalho praticada, qualquer efeito relacionado às fraturas verticais, de menor permeabilidade. Por outro lado, o DAEE (1979), no estudo das regiões administrativas 10 e 11, em escala maior (1:250.000), concluiu que os poços que exploram os basaltos próximos a lineamentos de drenagem são 10 vezes mais produtivos, em termos de capacidade específica, do que aqueles mais distantes destas feições, evidenciando a importância das fraturas verticais. 

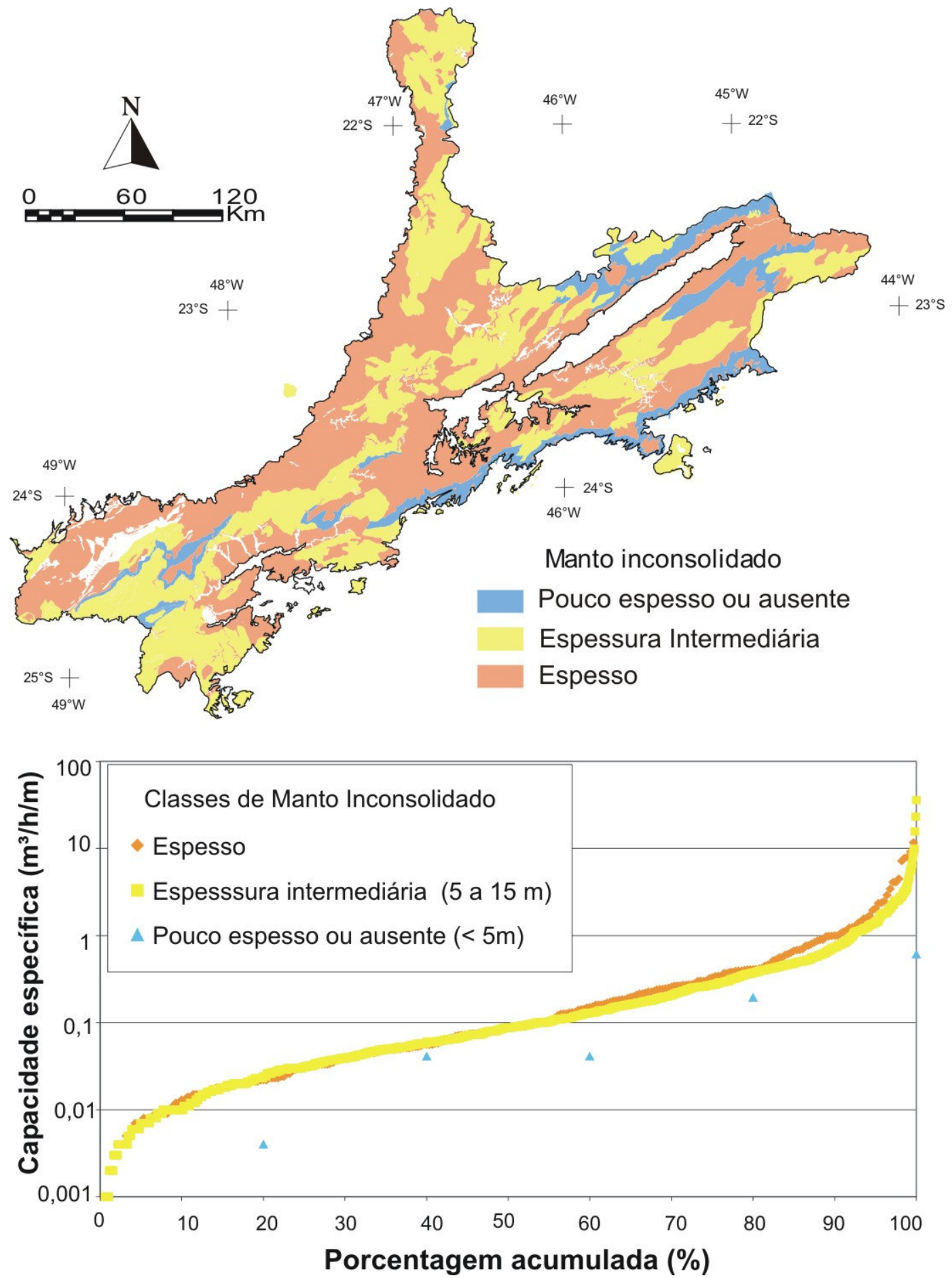

Figura 6. Curvas de distribuição acumulada obtidas para as várias classes de espessura de manto inconsolidado que ocorrem sobre os aquíferos fraturados pré-cambrianos do Estado de São Paulo e mapa de distribuição destas classes em área de rochas pré-cambrianas.

Figure 6. Cumulative distributions obtained for the various classes of the thickness of the unconsolidated materials which overlay the Precambrian fractured aquifers of the State of São Paulo and map of their distribution. 


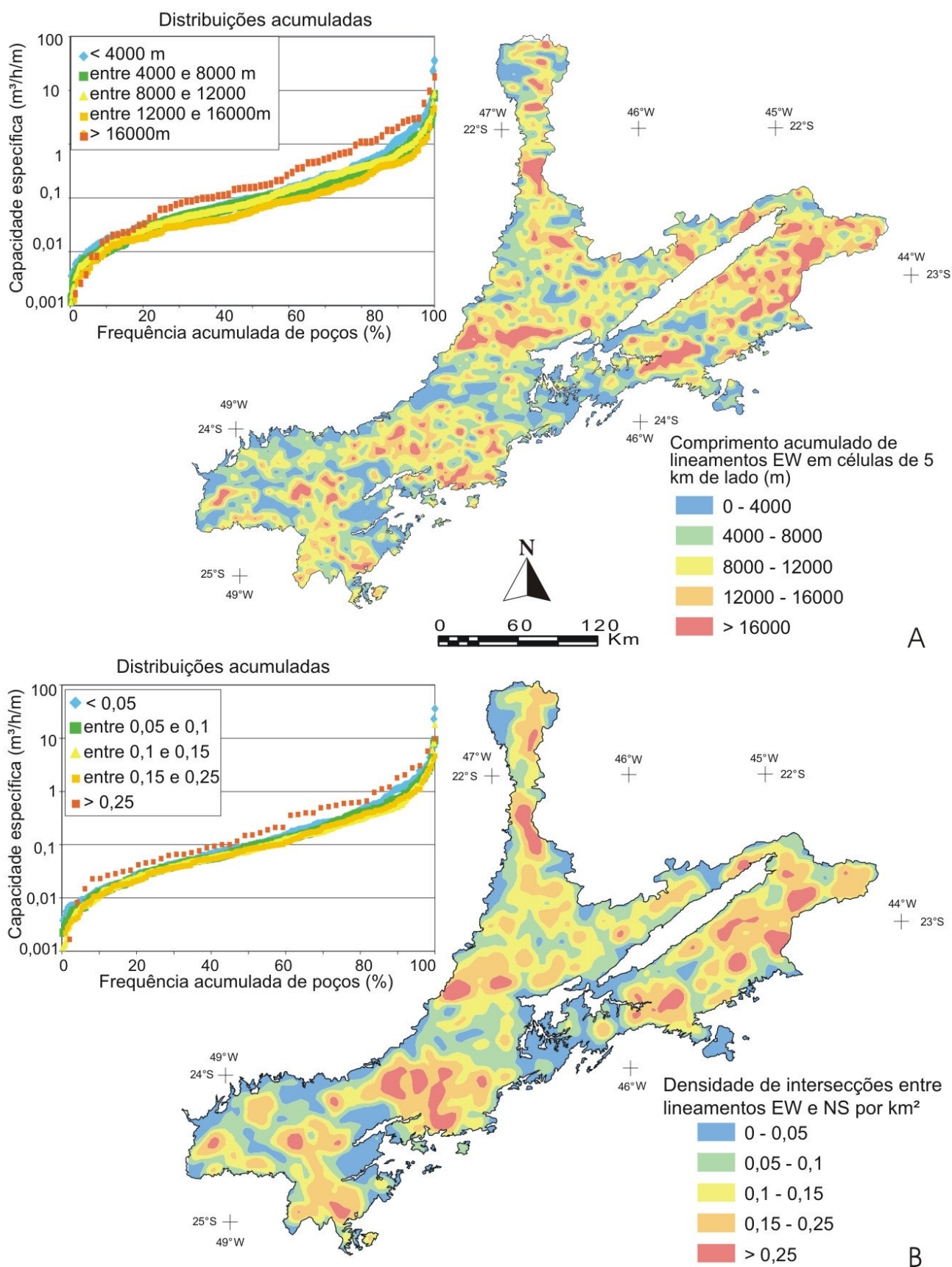

Figura 7. (A) Mapa de classes de densidade de lineamentos EW para as rochas pré-cambrianas e respectivas distribuições acumuladas. (B) Mapa de classes de densidade de intersecções de lineamentos EW e NS e respectivas distribuições acumuladas. As áreas com elevada densidade de intersecções de lineamentos EW e NS (> 0,25) coincidem, em grande parte, com áreas de maior densidade de lineamentos EW (> 1600) e apresentam potencial maior de produção de água subterrânea como mostrado pelas distribuições acumuladas.

Figure 7. (A) Map of EW lineament density for the precambrian rocks and respective cumulative distributions. (B) Map of $E W$ and NS lineament intersection density and respective cumulative distributions. The areas with the highest density of EW and NS lineamen intersection density $(>0,25)$ greatly coincide with the highest EW lineament density $(>1600)$ areas and present the largest groundwater production potential as shown by the cumulative distributions.

Finalmente, um último fator de análise foi o de blocos geológicos (ver definição na Tabela 2), que resultou, para as rochas pré-cambrianas não carbonáticas (granitos e rochas metamórficas de alto e baixo grau) na identificação e delimitação de quatro classes de potenciais hidrogeológicos distintos na área de ocorrência dos aqüíferos fraturados do Estado de São Paulo, apresentadas na Figura 8. Os basaltos e as rochas carbonáticas pré-cambrianas estão representados em curvas distintas, porém, devido ao comportamento hidráulico semelhante, estes dois tipos de rocha foram agrupados na quarta classe de potencialidade de produção. Da mesma forma, o Aquíffero Diabásio (Ksgd) e parte do Aquífero Pré-Cambriano $(\mathrm{p} €)$ foram agrupados na segunda 
classe de produção. Os resultados obtidos são bastante conclusivos para a porção central do Aqüífero p€, região de Lindóia/Campinas/Grande São Paulo, onde há maior quantidade de poços (Figura 2); para as demais regiões do Estado, onde a densidade de poços é muito baixa, os resultados são apenas indicativos.

Poços localizados a até $3 \mathrm{~km}$ de distância da Bacia do Paraná e a até $1 \mathrm{~km}$ de distância da Bacia de São Paulo também são significativamente mais produtivos, quando comparados aos das regiões circunvizinhas. Isto é ilustrado na Figura 9 e deve resultar da presença de poços mistos (explorando rochas sedimentares das bacias além de rochas pré-cambrianas) ou da presença de zonas de fraturas mais adensadas e/ou mais abertas relacionadas à evolução da borda das bacias. Estes poços foram eliminados da análise de blocos geológicos.

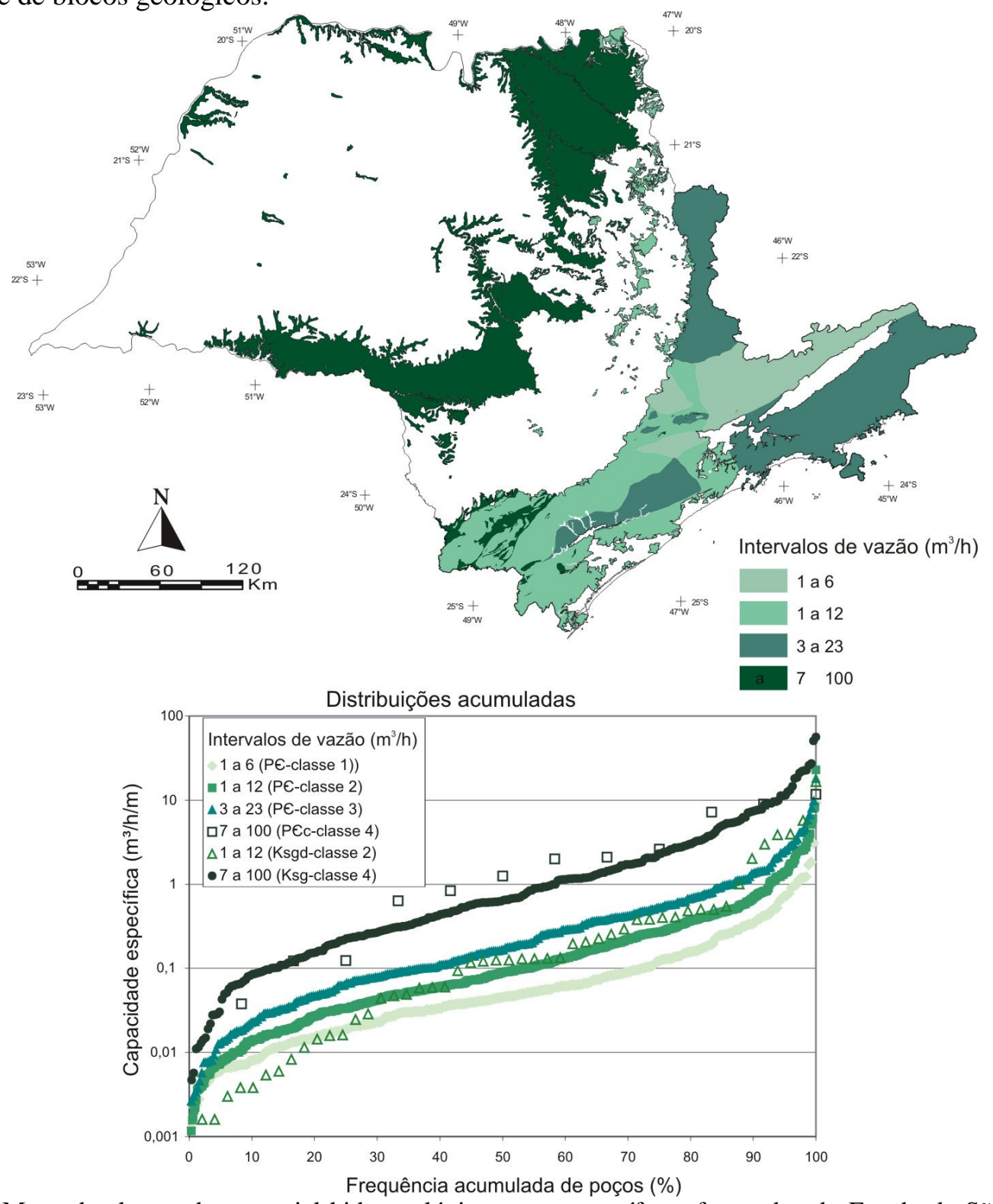

Figura 8. Mapa de classes de potencial hidrogeológico para os aquíferos fraturados do Estado de São Paulo e gráfico de distribuições acumuladas correspondentes.

Figure 8. Map of the hydrogeologic potential classes for the fractured aquifers of the State of São Paulo.
A partir das distribuições acumuladas das quatro classes definidas, foram identificados os valores de capacidades específicas em $20 \%, 50 \%$ e $80 \%$ da distribuição e convertidos para valores de vazão por meio de análise de correlação entre $\mathrm{Q}$ e $\mathrm{Q} / \mathrm{s}$, com grau de confiança de $95 \%$ (Tabela 4). Nesta análise utilizaram-se dados de poços com teste de bombeamento de duração igual ou superior a 20 horas, pois, nestes casos, as vazões praticadas seriam as mais indicadas para cada poço. As curvas e as respectivas equações, ilustradas na Figura 10, foram construídas apenas para os aquíferos Serra Geral (Ksg) e PréCambriano não Carbonático (p€), pois para os aquíferos Pré-Cambriano Carbonático (p€c) e Diabásio(Ksgd), a quantidade de poços com testes de bombeamento adequados era insuficiente. 


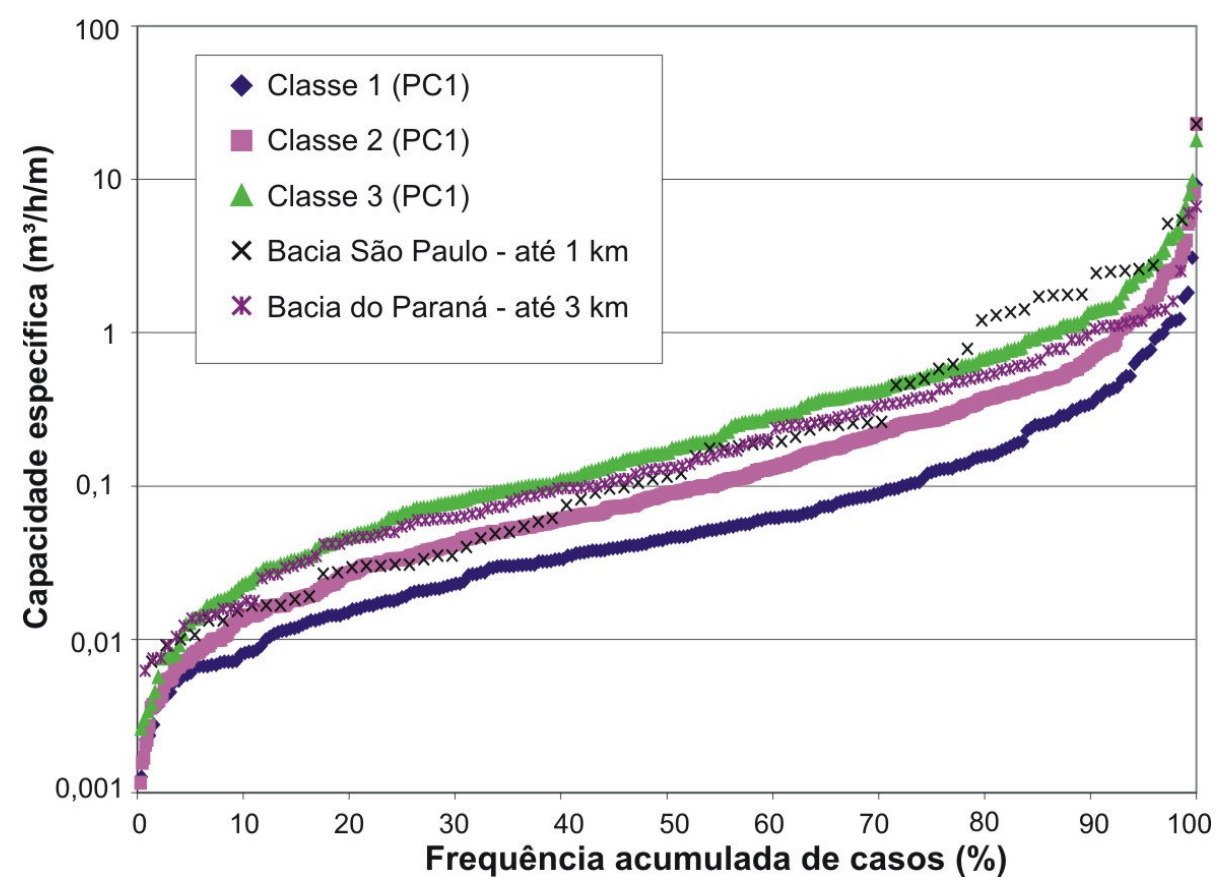

Figura 9. Distribuições acumuladas das classes de produção potencial para as rochas pré-cambrianas nãocarbonáticas obtidas com base na análise de blocos geológicos e de densidades de lineamentos e de intersecções de lineamentos; e distribuições acumuladas de poços localizados a até $3 \mathrm{~km}$ de distância da Bacia do Paraná e a até $1 \mathrm{~km}$ de distância da Bacia de São Paulo.

Figure 9. Cumulative distributions of the production potential classes for the non-carbonatic Precambrian rocks obtained through the analysis of the geological block and lineament density and lineament intersection density. The cumulative distributions for wells at a distance up to 3 and $1 \mathrm{~km}$ from the Parana and São Paulo basins, respectively, are also depicted.

Desta forma, no mapa de águas subterrâneas dos aquíferos fraturados do Estado de São Paulo distinguem-se áreas com vazões prováveis, nos intervalos de 20 a $80 \%$ da distribuição, entre 1 e $6 \mathrm{~m}^{3} / \mathrm{h}$ (classe 1 ), 1 e $12 \mathrm{~m}^{3} / \mathrm{h}$ (classe 2 ), 3 e 23 $\mathrm{m}^{3} / \mathrm{h}$ (classe 3) e 7 e $100 \mathrm{~m}^{3} / \mathrm{h}$ (classe 4 ). As rochas onde ocorrem estas faixas de vazão são mencionadas na Tabela 4 , onde são citadas também as medianas (valores centrais ou de $50 \%$ ). Apesar de não ter sido possível calcular os valores de vazão para o Ksgd (diabásio) e P€c, considerou-se que, devido à semelhança de suas curvas de distribuição acumulada com as da classe 2 do Aqüífero $\mathrm{p} €$ e do Aqüífero Ksg, respectivamente, poderiam ser-lhes atribuídas às mesmas faixas de vazão.

Tabela 4. Valores de 20\%, 50\% (mediana) e $80 \%$ para as curvas de distribuição acumulada obtidas em cada aquíf́ero fraturado e para os poços localizados a 1 e $3 \mathrm{~km}$ de distância das bacias de São Paulo e do Paraná, respectivamente.

\begin{tabular}{|c|c|c|c|c|c|c|c|c|c|}
\hline & \multicolumn{3}{|c|}{$\begin{array}{c}\text { Capacidade } \\
\text { específica }(\mathrm{Q} / \mathrm{s}) \text {, } \\
\left(\mathrm{m}^{3} / \mathrm{h} / \mathrm{m}\right)\end{array}$} & \multicolumn{3}{|c|}{$\begin{array}{c}\text { Vazão }(\mathrm{Q}) \\
\text { calculada por } \\
\text { correlação }\left(\mathrm{m}^{3} / \mathrm{h}\right)\end{array}$} & \multirow[t]{2}{*}{$\begin{array}{l}\text { Número de } \\
\text { Poços }\end{array}$} \\
\hline Aqüífero & Grupos de Rochas & & $20 \%$ & $50 \%$ & $80 \%$ & $20 \%$ & $50 \%$ & $80 \%$ & \\
\hline \multirow{3}{*}{$\mathrm{P} €$} & \multirow{3}{*}{$\begin{array}{l}\text { Rochas metamórficas } \\
\text { e granitos }\end{array}$} & Classe 1 & 0,01 & 0,04 & 0,14 & 1 & 2 & 6 & 199 \\
\hline & & Classe 2 & 0,02 & 0,08 & 0,33 & 1 & 4 & 12 & 544 \\
\hline & & Classe 3 & 0,05 & 0,18 & 0,67 & 3 & 7 & 23 & 236 \\
\hline Ksgd & Diabásios & Classe 2 & 0,01 & 0,13 & 0,48 & \multicolumn{3}{|c|}{ Não calculada* } & 49 \\
\hline Ksg & Basaltos & Classe 4 & 0,16 & 0,62 & 2,89 & 7 & 23 & 100 & 285 \\
\hline $\mathrm{P€c}$ & Rochas Carbonáticas & Classe 4 & 0,12 & 1,25 & 7 & \multicolumn{3}{|c|}{ Não calculada* } & 12 \\
\hline \multicolumn{3}{|c|}{ Poços a até $3 \mathrm{~km}$ de distância da Bacia do Paraná } & 0,04 & 0,13 & 0,53 & \multicolumn{3}{|c|}{ Não calculada* } & 137 \\
\hline \multicolumn{3}{|c|}{$\begin{array}{l}\text { Poços a até } 1 \mathrm{~km} \text { de distância da Bacia de São } \\
\text { Paulo }\end{array}$} & 0,03 & 0,12 & 1,29 & \multicolumn{3}{|c|}{ Não calculada* } & 74 \\
\hline
\end{tabular}

* Explicado no texto 

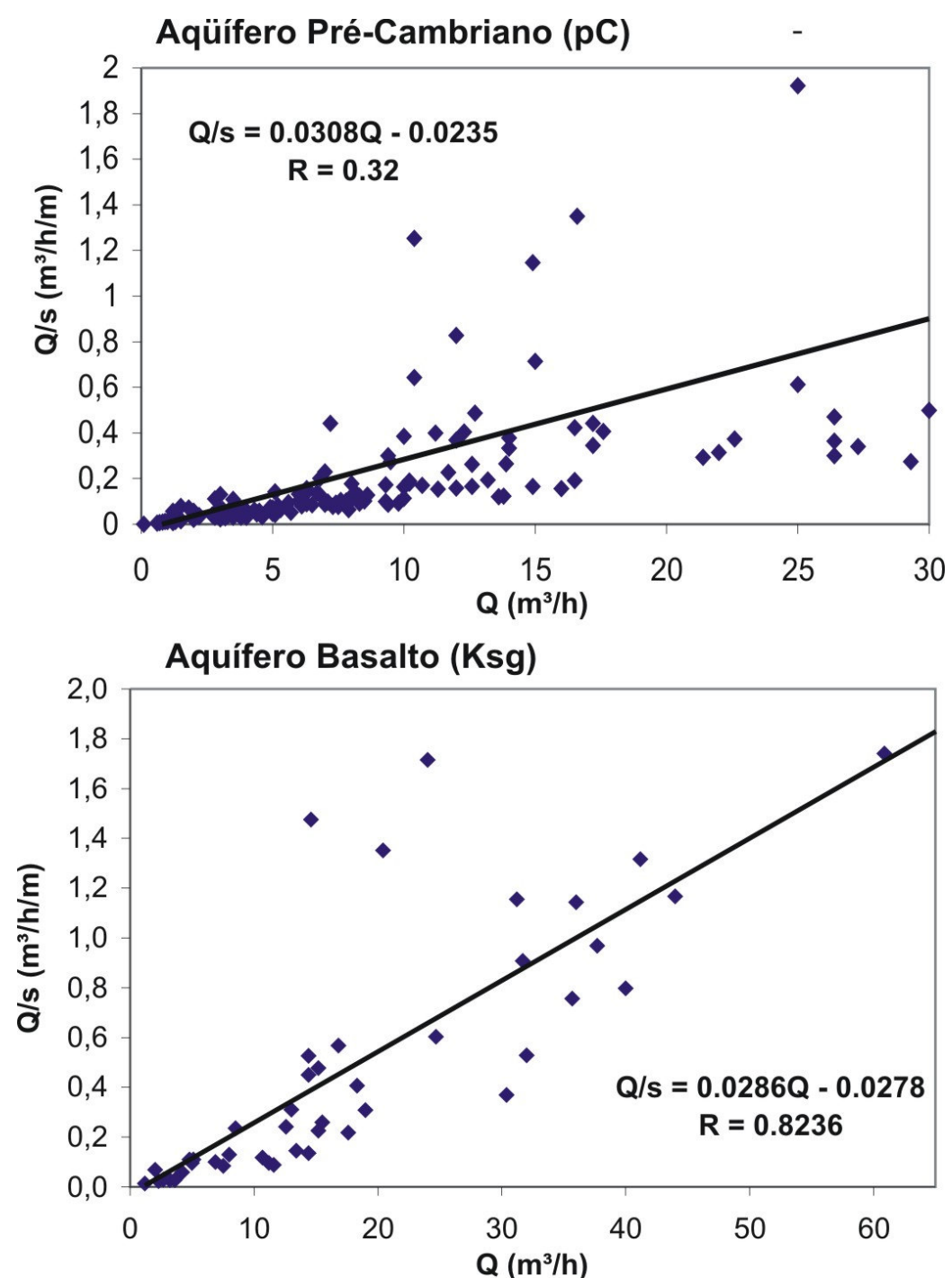

Figura 10. Gráfico e equação de correlação da variação de Q/s (capacidade específica) com Q (vazão) feita com base em dados de poços com teste de bombeamento igual ou superior a 20h, para os aqüíferos Pré-Cambriano e Basalto.

\section{DISCUSSÃO E CONCLUSÕES}

A avaliação do parâmetro capacidade específica, das rochas pré-cambrianas não carbonáticas (granitos e rochas metamórficas de alto a baixo grau) do Estado de São Paulo, revelou que, na escala de análise utilizada (1:1.000.000), o fator blocos geológicos é mais efetivo que a litologia, densidade e intersecção de lineamentos e espessura de manto inconsolidado para a delimitação de regiões com potenciais distintos de produção. Tais blocos são balizados ou por limites entre terrenos pré-cambrianos (zonas de cisalhamento originalmente desenvolvidas no final do Proterozóico e início do Fanerozóico) ou por lineamentos que supostamente representam estruturas rúpteis importantes. O papel desempenhado por tais limites ainda não é bem compreendido, no entanto sugerem que a história tectônica tem papel fundamental para a existência de regiões com potencialidades distintas nos aqüíferos fraturados pré-cambrianos do Estado de São Paulo (Fernandes 2006).

É de senso comum que as propriedades hidráulicas dos aqüíferos em questão são controladas por fraturas e que a condutividade hidráulica destas é governada pelas suas aberturas atuais. Uma vez que tais aberturas devem, em grande parte, ser controladas pela atividade de eventos tectônicos cenozóicos (Fernandes 1997, Fernandes; Rudolph 2001), supõe-se que as descontinuidades que limitam as regiões pré-cambrianas de diferentes produtividades, incluindo as zonas de cisalhamento (ZCs) que limitam terrenos précambrianos, tenham atuado durante o Cenozóico influenciando a distribuição, densidade, conectividade e abertura das fraturas. A 
descontinuidade que coincide com o limite noroeste da bacia de Taubaté tem clara relação com o Cenozóico, pois atuou durante a evolução daquela bacia. O limite que coincide com lineamentos de direção NS, que passam por Itatiba e Campo Limpo Paulista (a norte da ZC Jundiuvira), é claramente rúptil, discordante das estruturas dúcteis e dúcteis-rúpteis précambrianas, com evolução, provavelmente, mais jovem. Também foram identificados outros limites que não coincidem nem com as zonas de cisalhamento dúctil-rúpteis nem com lineamentos importantes; estes limites apresentam principalmente a direção NW e secundariamente WNW e NS, passando por São Lourenço da Serra e próximo a São Bernardo do Campo (entre as ZCs Cubatão e Caucaia), próximo a Ibiúna (entre as ZCs Caucaia e Taxaquara), por Caieiras (entre ZCs Taxaquara e Jundiuvira) e próximo a Itupeva (a norte da ZC Jundiuvira).

A única área em que a análise de lineamentos resultou na delimitação de zonas mais produtivas, situadas entre Caieiras e Sorocaba, é um domínio estrutural onde predominam as direções EW e NS, relacionáveis a evento tectônico quaternário que gerou e reativou falhas de mesma direção. Este evento, amplamente reconhecido no Estado de São Paulo e estados vizinhos, é geralmente descrito como trans-extensional, característica que provavelmente propiciou maior e mais generalizada abertura das suas fraturas extensionais, de direção NW-SE, paralelas ao seu esforço máximo principal. Assim, os domínios onde este evento predomina poderiam apresentar circulação mais rápida e maior armazenamento de água subterrânea. Fernandes (1997) e Fernandes; Rudolph (2001), ao utilizarem fotos aéreas na escala 1:25.000, onde é possível identificar em qual lineamento cada poço está situado, mostraram que, dentro de domínios estruturais onde predominam as direções EW e NS, poços associados a lineamentos NW (prováveis fraturas extensionais) são mais produtivos. No entanto, os mesmos autores apontaram que, em outros domínios tectônicos, a direção NNE é mais favorável. Na área préCambriana da porção paulista das bacias dos rios Mogi-Guaçu e Pardo, Perrotta; Salvador (2002, 2006) identificaram como mais produtivas as regiões onde fraturas de direção próxima a N30W se associavam à direção N45E. Assim, nota-se que a atuação de vários eventos cenozóicos variando de intensidade e campos de esforços de uma região para outra no Estado, dificulta a relação com a produtividade dos poços, principalmente numa avaliação em escala regional.

Apesar de bastante provável, a associação entre os eventos cenozóicos e a geração e/ou reativação de estruturas que possam constituir os caminhos preferenciais de circulação da água subterrânea, não está clara, sendo evidente a necessidade de estudos detalhados que elucidem e caracterizem as relações existentes entre as propriedades hidráulicas dos aquíferos fraturados e as direções estruturais. 


\section{REFERÊNCIAS}

BERTACHINI, A.C. Estudo das características hidrogeológicas dos terrenos cristalinos sob clima úmido, na região de Jundiaí. São Paulo, 1987, 180 f. Dissertação de Mestrado. Instituto de Geociências USP.

DAEE - DEPARTAMENTO DE ÁGUAS E ENERGIA ELÉTRICA. Estudo de Águas Subterrâneas - Regiões Administrativas 10 e 11Presidente Prudente/Marília. Secretaria dos Serviços e Obras Públicas/DAEE, São Paulo, 3V, 1979.

DAEE - DEPARTAMENTO DE ÁGUAS E ENERGIA ELÉTRICA. Estudo de Águas Subterrâneas - Região Administrativa 5 Campinas. Secretaria dos Serviços e Obras Públicas/DAEE, São Paulo, 2V, 1981.

DAEE - DEPARTAMENTO DE ÁGUAS E ENERGIA ELÉTRICA. Estudo de Águas Subterrâneas - Região Administrativa 4 Sorocaba. Secretaria dos Serviços e Obras Públicas/DAEE, São Paulo, 2V, 1982.

FERNANDES, A.J.; RUDOLPH, D. The influence of Cenozoic Tectonics on the groundwater-production capacity of fractured zones: a case study in Sao Paulo, Brazil. Hydrogeology Journal, n.9, p.151-167, 2001. FERNANDES, A.J. Tectônica cenozóica na porção média da bacia do rio Piracicaba e sua aplicação à hidrogeologia de meios fraturados. São Paulo, 1997, 244 f. Tese, Instituto de Geociências-USP.

FERNANDES, A.J. Fatores que influenciam a produção de poços em aqüíferos fraturados cristalinos e métodos de investigação. In: CONGRESSO BRASILEIRO DE ÁGUAS SUBTERRÂNEAS, 2006, Curitiba, Anais...Curitiba, ABAS, 2006. Em CD-ROM, p. 32-38.

FERNANDES, A.J.; PERROTTA, M.M.; SALVADOR, E.D.; AZEVEDO, S.G.; GIMENEZ FILHO, A.; STEFANI, F.L.; PAULON, N Aqüíferos Fraturados. In: GOVERNO DO ESTADO DE SÃO PAULO, Mapa de águas subterrâneas do Estado de São Paulo em 1:1.000.000. DAEE/IGSMA/IPT/CPRM, São Paulo. Nota explicativa. 2005. GOVERNO DO ESTADO DE SÃO PAULO Mapa de águas subterrâneas do Estado de São Paulo em 1:1.000.000. DAEE/IG-SMA/IPT/CPRM, São Paulo. Nota explicativa e 2 anexos (mapa e CD-ROM), 2005. IG - INSTITUTO GEOLÓGICO. Zoneamento das áreas de recarga dos aqü[iferos do balneário do município de Águas de Lindóia. São Paulo, 1997. Projeto Concluído.

IG - INSTITUTO GEOLÓGICO. Estudo geológico e hidrogeológico do município da estância hidromineral de Poá. São Paulo, 2000. Projeto Concluído.

IG - INSTITUTO GEOLÓGICO. Mapeamento da vulnerabilidade natural dos aquíferos fraturados pré-cambrianos da Região Metropolitana de
Campinas. Instituto Geológico-SMA/FEHIDRO, São Paulo, 2002. Projeto Concluído.

IG - INSTITUTO GEOLÓGICO. Rotina "lineamentos" desenvolvida em Mapinfo para cálculo de densidade de lineamentos, densidade de intercsecções de lineamentos e elaboração de rosáceas para polígonos definidos. IG-SMA/GEOJÁ MAPAS DIGITAIS LTDA. 2004.

IRITANI, M.A. et al. Delimitação da área de recarga de fontes de aqüífero fraturado. In: CONGRESSO BRASILEIRO DE ÁGUAS SUBTERRÂNEAS, 1998, São Paulo, Anais...São Paulo, ABAS, 1998. 1 CD-ROM, p. 32-38.

MADRUCCI, V. Prospecção de água subterrânea em terreno cristalino utilizando-se análise integrada de dados de sensoriamento remoto, geofísicos e técnicas de geoprocessamento, região de Lindóia, SP. São Paulo, 2004. Tese. Instituto de Geociências - USP.

MANCUSO, M.; CAMPOS, J.E. Aqüífero Bauru. In: GOVERNO DO ESTADO DE SÃO PAULO, Mapa de águas subterrâneas do Estado de São Paulo em 1:1.000.000. DAEE/IG-SMA/IPT/CPRM, São Paulo. Nota explicativa. 2005.

MENEGASSE, L.N. Estudo hidrogeológico das rochas metassedimentares do Grupo São Roque a NW da Grande São Paulo: critérios para locação de poços profundos. São Paulo, 1991, 104 f. Dissertação. Instituto de Geociências - USP.

PERROTTA, M.M. et al. Mapa Geológico do Estado de São Paulo, escala 1:750.000. São Paulo, CPRM (Programa Levantamentos Geológicos Básicos do Brasil). 2005

PERROTTA, M.; SALVADOR, E. D. Avaliação regional do potencial de produtividade de aquíf́ros cristalinos em um sistema de informações geográficas (SIG). In: CHAVES, J.M; FRANCA-ROCHA, W. Geotecnologias: Trilhando novos caminhos nas geociências. Salvado,: SBG-Núcleo Bahia-Sergipe, 2006.

PERROTTA, M.M.; SALVADOR, E.D. 2002. Avaliação regional do potencial de produtividade de aqüíferos cristalinos em um Sistema de Informações Geográficas (SIG). In: CONGRESSO BRASILEIRO DE GEOLOGIA, 2002, João Pessoa, Anais... João Pessoa, SBG, 2002. 1 CD-ROM, p. 166-166.

QUADROS, E.F.; CORRÊA FILHO, D.; TAIOLI, F.; PEREIRA JUNIOR, G.G. 3-D hydraulic tests on weathered-fractured basalt - Brazil. In: INTERNATIONAL CONGRESS ON ROCK MECHANICS, 1991, Aachen, Proceedings... Aachen, International Society of Rock Mechanics, 1991.

REBOUÇAS, A.C. Potencialidade hidrogeológica dos basaltos da Bacia do Paraná no Brasil. In: CONGRESSO BRASILEIRO DE GEOLOGIA, 1978, Recife, Anais... Recife, SBG, 1978. 1 CD-ROM, v.6, p.2963-2976. 
SINELLI, O. Água subterrânea no município de Ribeirão Preto. In: CONGRESSO BRASILEIRO DE GEOLOGIA, 1971, São Paulo, Anais... São Paulo, SBG, 1971. 1 CD-ROM, p.17-34.

TAKAHASHI, A. T.; PERROTTA, M. M.; SALVADOR, E. D. Hidrogeologia das bacias de drenagem dos Rios Mogi-Guaçu e Pardo, SP. São Paulo, 2003. Projeto Mogi-Guaçu/Pardo. CPRM Secretaria de Estado do Meio Ambiente-SP.

TRESSOLDI, M. Uma contribuição à caracterização de maciços rochosos fraturados visando a proposição de modelos para fins hidrogeológicos e hidrogeotécnicos. São Paulo, 1991, 291 f. Dissertação. Escola Politécnica- USP.

\section{AGRADECIMENTOS}

Agradecemos à equipe e instituições que trabalharam na elaboração do Mapa de Águas Subterrâneas do Estado de São Paulo e em especial ao geólogo José Eduardo Campos que muito contribuiu para o entendimento dos dados do cadastro de poços do DAEE, peça fundamental para a realização do zoneamento dos diferentes potenciais dos aqüíferos fraturados do Estado. Também agradecemos ao Dr. Luiz Carlos Ferrari que contribuiu para a análise estatística da produção dos poços. 